\title{
Maximum Concentration Normalized by Weight
}

National Cancer Institute

\section{Source}

National Cancer Institute. Maximum Concentration Normalized by Weight. NCI

Thesaurus. Code C92373.

The maximum concentration occurring at T max, divided by the weight. 